\title{
Integration of balance and strength training into daily life activity to reduce rate of falls in older people (the LiFE study): randomised parallel trial
}

\author{
OPEN ACCESS
}

\author{
Lindy Clemson professor of occupational therapy and ageing ${ }^{12}$, Maria A Fiatarone Singh john sutton \\ chair of exercise and sport science, professor of medicine ${ }^{2}$, Anita Bundy professor of occupational \\ therapy ${ }^{2}$, Robert G Cumming professor of epidemiology and geriatric medicine ${ }^{3}$, Kate Manollaras \\ research assistant ${ }^{2}$, Patricia O'Loughlin physiotherapist ${ }^{2}$, Deborah Black biostatistician, professor, \\ and chair of health data management ${ }^{2}$
}

${ }^{1}$ Ageing, Work, and Health Research Unit and the Centre for Excellence in Population Ageing Research, Faculty of Health Sciences, University of Sydney, Lidcombe, 2141 New South Wales, Australia ; ${ }^{2}$ Faculty of Health Sciences, University of Sydney ; ${ }^{3}$ Centre for Education and Research on Ageing (CERA) and Faculty of Medicine, University of Sydney, Sydney, New South Wales

\begin{abstract}
Objectives To determine whether a lifestyle integrated approach to balance and strength training is effective in reducing the rate of falls in older, high risk people living at home.

Design Three arm, randomised parallel trial; assessments at baseline and after six and 12 months. Randomisation done by computer generated random blocks, stratified by sex and fall history and concealed by an independent secure website.

Setting Residents in metropolitan Sydney, Australia.

Participants Participants aged 70 years or older who had two or more falls or one injurious fall in past 12 months, recruited from Veteran's Affairs databases and general practice databases. Exclusion criteria were moderate to severe cognitive problems, inability to ambulate independently, neurological conditions that severely influenced gait and mobility, resident in a nursing home or hostel, or any unstable or terminal illness that would affect ability to do exercises.

Interventions Three home based interventions: Lifestyle integrated Functional Exercise (LiFE) approach ( $n=107$; taught principles of balance and strength training and integrated selected activities into everyday routines), structured programme ( $n=105$; exercises for balance and lower limb strength, done three times a week), sham control programme $(n=105$; gentle exercise). LiFE and structured groups received five sessions with two booster visits and two phone calls; controls received three home visits and six phone calls. Assessments made at baseline and after six and 12 months.
\end{abstract}

Main outcome measures Primary measure: rate of falls over 12 months, collected by self report. Secondary measures: static and dynamic balance; ankle, knee and hip strength; balance self efficacy; daily living activities; participation; habitual physical activity; quality of life; energy expenditure; body mass index; and fat free mass.

Results After 12 months' follow-up, we recorded 172, 193, and 224 falls in the LiFE, structured exercise, and control groups, respectively. The overall incidence of falls in the LiFE programme was 1.66 per person years, compared with 1.90 in the structured programme and 2.28 in the control group. We saw a significant reduction of $31 \%$ in the rate of falls for the LiFE programme compared with controls (incidence rate ratio 0.69 (95\% confidence interval 0.48 to 0.99$)$ ); the corresponding difference between the structured group and controls was non-significant $(0.81$ (0.56 to 1.17)). Static balance on an eight level hierarchy scale, ankle strength, function, and participation were significantly better in the LiFE group than in controls. LiFE and structured groups had a significant and moderate improvement in dynamic balance, compared with controls.

Conclusions The LiFE programme provides an alternative to traditional exercise to consider for fall prevention. Functional based exercise should be a focus for interventions to protect older, high risk people from falling and to improve and maintain functional capacity.

Trial registration Australia and New Zealand Clinical Trials Registry 12606000025538.

\section{Introduction}

Falling in older age has debilitating and isolating social consequences, along with high and escalating economic costs. ${ }^{12}$ Falls can start a downward spiral of immobility, reduced confidence, and incapacity leading to institutionalisation. Fall related admissions have not declined over the past ten years, ${ }^{3}$ and there is an imperative to develop effective strategies for fall 
prevention that are acceptable and sustainable over the long term for older people.

The optimum exercise modality for falls prevention in older adults has been defined as balance enhancing activity and lower limb resistance training. ${ }^{4}$ However, the number of older people that routinely engage in strength training remains low at less than $10 \%{ }^{5}$ and possibly much lower for activities that challenge balance. Those people older than 70 years who do engage in balance and resistance training are much more likely to be healthy and functionally capable than those who do not.

Integration of exercise into lifestyle activities could enhance exercise adoption and adherence in other cohorts, ${ }^{6-8}$ but this approach has never been investigated in frail, older people at risk for falls. Therefore, we designed and tested the Lifestyle integrated Functional Exercise ( $\mathrm{LiFE}$ ) programme, which embeds balance and lower limb strength training into habitual daily routines. In a small pilot study, ${ }^{9}$ this alternate approach to traditional exercise had high potential to reduce falls (incidence rate ratio $0.23,95 \%$ confidence interval 0.07 to 0.83 ), and a larger trial was needed to confirm the new approach's effectiveness compared with placebo and to determine mechanisms of benefit.

We hypothesised that a lifestyle integrated approach (using the LiFE programme) to balance and strength training would be more effective than a sham control programme (comprising of gentle exercise) in reducing falls in high risk people aged 70 years and over and living at home over one year. We further hypothesised that a traditional structured exercise programme would be as effective as LiFE in reducing falls, compared with the control programme; that intermediate outcomes of strength, balance, functional capacity, and quality of life would show equal benefit in LiFE participants compared with the structured programme; and that balance confidence in daily tasks and habitual physical activity levels would improve to a greater extent from the LiFE programme than from either the traditional or the control programme.

\section{Methods}

\section{Trial design}

We conducted a three arm, randomised parallel trial with assessments measured at baseline, six months, and 12 months after randomisation. The study was approved by the University of Sydney human research ethics committee and registered on 20 January 2006.

\section{Participant recruitment, randomisation, and blinding}

Participants were recruited by mailings to Department of Veteran's Affairs (DVA) Databases across the metropolitan area of Sydney, Australia, and three general practice databases inviting them to participate. DVA databases included veterans, their spouses, and war widows. Inclusion criteria were men and women aged 70 years or older and who had two or more falls or one injurious fall in the past 12 months, which was determined by self report. Exclusion criteria were moderate to severe cognitive problems ( $<$ two errors on the short portable mental status questionnaire), no conversational English, inability to ambulate independently, a neurological condition which severely influenced their gait and mobility (for example, Parkinson's disease that results in very specific patterns of movements, mobility and visuospatial disturbances that indicate specific interventions), resident in a nursing home or hostel, or any unstable or terminal illness that would preclude the planned exercises and was unlikely to resolve (for example, aortic aneurysm, malignant arrhythmias, critical aortic stenosis, rotator cuff tear, and active hernias).

Randomisation was generated by an investigator not involved in data collection or intervention, who used Stata 7 and the add on program Ralloc ${ }^{10}$ to generate random block groups of three and six, and stratified by sex and history of fall (that is, one or two falls, or three or more falls) in a 1:1:1 ratio. The randomisation was conducted after baseline assessment and concealed by using an automated secure website that was operated by an off-site independent service. All assessments at six and 12 month follow-up, conducted on a home visit, and fall event surveillance were conducted by a research assistant blinded to group allocation. All data was also entered and checked by a blinded research assistant.

\section{Interventions}

In the LiFE approach, movements specifically prescribed to improve balance or increase strength are embedded within everyday activities, so that the movements can be done multiple times during the day. Rather than a prescribed set of exercises conducted several times a week, LiFE activities occur whenever the opportunity arises during the day. The strategies to improve balance include "reduce base of support", "move to limits of sway", "shift weight from foot to foot", "step over objects", and "turning and changing direction". A prescribed activity incorporating the strategy of "reducing base of support" might involve a tandem stand while working at the kitchen bench, and over time could be upgraded to working while standing on one leg. Strategies to increase strength include "bend your knees", "on your toes", "up the stairs", "on your heels", "sit to stand", "walk sideways", and "tighten muscles". A prescribed activity incorporating the strategy of "bend knees" might involve squatting instead of bending at the waist to close a drawer, and could be upgraded to picking things up from the floor. The LiFE training focuses on instituting new habitual behaviours within selected situational contexts that serve as prompts for action. ${ }^{911}$

Everyday activities that were altered for LiFe participants were determined through self report using a weekly planner and interview. We used an assessment tool designed for this study to establish the difficulty level of the strategy incorporated into everyday activity. ${ }^{12}$ The movements embedded in everyday activity were discussed on each visit and revised as necessary. Participants manuals provide examples of each balance and strength strategy across a range of daily activities and situations, with ideas for increasing intensity and challenge. ${ }^{13}$ The manuals were used in the teaching and planning of the individualised programme.

The structured programme ${ }^{14}$ involved seven exercises for balance and six for lower limb strength using ankle cuff weights and performed three times a week. These exercises used the principles of maintaining training in the "hard zone" and similar to other successful exercise regimens in fall prevention. The LiFE and structured programmes were taught over five sessions with two booster sessions and two follow-up phone calls over a six month period. Both programmes were prescribed, tailored, and upgraded. Ample evidence from home based structured programmes indicates that this dosage is feasible and cost effective. ${ }^{15}$ The control programme (two sessions, one booster session, and six follow-up phone calls) comprised 12 gentle and flexibility exercises while seated, lying down, or standing while holding on (for example, hip rotation, leg swings). Exercises were not upgraded - that is, not altered in any way (such as changing the number of repetitions or increasing the challenge 
to balance). The reduced time given to the control intervention was appropriate because this programme was much simpler and easier to teach. Interventionists, trained in each of the interventions, included physiotherapists and occupational therapists.

\section{Outcome measures}

\section{Fall surveillance}

A fall was defined as a person unintentionally coming to rest on the ground, floor, or other lower level. Falls were recorded by daily calendar, which were mailed monthly using preaddressed envelopes. A research assistant blinded to group allocation telephoned participants if they failed to return the calendar to ascertain whether they had fallen. Exercise adherence was monitored by weekly logs returned monthly by post to the interventionists once weekly visits ceased.

\section{Balance and strength}

Postural control was defined as either static balance (where balance is measured in a standing position) or dynamic balance (where postural control is challenged during movement involving walking). Static balance was assessed using two hierarchical balance scales. The first was a five level scale from the short physical performance battery-balance test, ${ }^{16}$ and the second was an eight level scale that incorporated challenging tasks at a higher level (such as "tandem stand eyes closed", "one leg stand with cognitive distracter") and used cut-off values of 10 or 15 seconds. We developed the second scale before analysis by using Rasch modelling ${ }^{17}$ to test the ordering of responses, which required the collapsing of several higher level items to construct the eight hierarchy levels. Dynamic balance was measured by a $3 \mathrm{~m}$ tandem walk time and errors. Maximal isometric lower limb strength was determined by the highest of three measurements obtained using a Chatillon DMG250 dynamometer with a custom made portable stand to eliminate variability in examiner strength.

\section{Functional outcomes, other outcomes, and participant characteristics}

We assessed balance self efficacy using the Activities Specific Balance Confidence (ABC) Scale. ${ }^{18}$ Functional limitation in capacity for daily life activities was measured by the Late Life Function Index ${ }^{19}$ and the NHANES independence measure for activities of daily life. ${ }^{20}$ The Late Life Disability Index measured limitation and frequency of participation in life tasks across personal, social, and community domains. ${ }^{21}$ We used the Physical Activity Scale for the Elderly ${ }^{22}$ to measure habitual physical activity, the Paffenbarger physical activity index ${ }^{23}$ to capture energy expenditure, and Life Space Assessment to determine the distance travelled within and from the home. ${ }^{24}$

We assessed health related quality of life with the five item EQ-5D instrument and global health status with the EQ-VAS scale. ${ }^{25}$ Body mass index was calculated from body height and weight, the latter using a calibrated electronic portable scale. Bioelectrical impedance analysis ${ }^{26}$ measured body composition (fat free mass) using an Impedimed DF50 device on the right wrist and ankle and with the person supine on a bed.

For participants' characteristics, we collected demographic information and medical history during interviews and recorded levels of depression via the geriatric depression scale.

\section{Statistical analysis}

We compared the rates of falls in the LiFE and structured interventions with those from the control intervention (that is, gentle exercise) using the negative binomial regression model (Stata, version 11). ${ }^{27}$ The model uses a Poisson distribution of fall events accounting for overdispersion, which incorporates both number of falls and time (days) followed up. We monitored fall events for one year or until the person withdrew from the study, was lost to follow-up, or died. An a priori power calculation indicated that we would need 110 participants in each group $(n=330)$ to detect a $33 \%$ relative reduction in fall rate (from $60 \%$ to $40 \%$ ) in each intervention group compared with the control group $(\beta=0.20, \alpha=0.05)$. We estimated that about $60 \%$ of control participants would have at least one fall during the year of follow-up, in view of the at-risk sample targeted. This estimate did not include dropout rates, which was $10 \%$ for falls data in our study, indicating a sample of 363 participants. Therefore, we recruited $87 \%$ of the target sample. For secondary outcomes, we used the general linear modelling, repeated measures procedure (SPSS, version 17.0) to establish the effects of interventions over time compared with the control group. The reported $\mathrm{F}$ ratio is a measure of the variation between groups divided by the variation within groups. We conducted a three way comparison, and if the main timextreatment effect was significant, or if indicated by significant retrospective Scheffe or Tukey tests, we examined pairwise comparisons between the interventions and control. We aimed to establish whether the change in one intervention was significantly greater than the control group over the 12 month follow-up-that is, if retrospective linear contrasts (rather than quadratic contrasts) were significant, which would indicate change over time rather than just a difference at one time point. We analysed rank order categorical data using a polynomial regression model. Finally, we determined effect sizes for significant pairwise results using a formula for Cohen's d. ${ }^{28}$

To calculate the proportion of exercises adhered to during the full first six months, we divided the number of exercises per set performed in each session by the number needed to be performed. The LiFE programme activities, which could be performed daily, were recoded to correspond with the other two programmes (up to one day of activities performed in the LiFE programme $=0$ times per week of exercises performed in other two programmes, two to three days=one time per week, four to five days=two times per week, and six to seven days=three times per week). We used a one way analysis of variance with retrospective analysis, and subsequent $t$ tests, to determine any differences. To establish exercise maintenance at 12 months, we examined adherence in the final (12th) month of follow-up.

\section{Results}

\section{Participant characteristics and tracking through trial}

The figure $\Downarrow$ tracks the participants through the trial. The major reason for not including people in the trial was that they did not meet the inclusion criteria for previous multiple falls in the past year or an injurious fall $(62.2 \%, \mathrm{n}=370)$. Other reasons were that participants were unable to independently ambulate $(8.7 \%$, $\mathrm{n}=52)$, had an illness or condition precluding exercise $(7.6 \%$, $\mathrm{n}=45)$, were in a hostel or nursing home $(6.4 \%, \mathrm{n}=38)$, had a neurological condition influencing gait or mobility $(6.4 \%, \mathrm{n}=38)$, were cognitively impaired $(3.9 \%, \mathrm{n}=23)$, were vision impaired or deaf $(2.7 \%, \mathrm{n}=16)$, were already involved in fall prevention programmes $(2.0 \%, \mathrm{n}=12)$, or lived outside the metropolitan area $(0.2 \%, \mathrm{n}=1)$. The sample recruited (mean age 83.4 years) 
was a high risk group, with $60 \%(n=191)$ reporting a history of recurrent falls and just over $90 \%(n=290)$ having had an injurious fall in the past year.

We recruited and randomised 317 people from February 2006 to December 2007. We saw no important differences between intervention or control groups in baseline measures (table $1 \Downarrow$ ). The fall data outcomes were missing for $31(10 \%)$ randomised participants. For the secondary measures, 76 (24\%) participants were not available at the final 12 month assessment. Since the frequency and causes of missed assessments were similar between groups (fig 1), we did a "complete case" intention to treat analysis. ${ }^{29}$

\section{Falls outcome}

After 12 months of follow-up, we recorded 172 falls in the LiFE group, 193 in the structured exercise group, and 224 falls in the control group. The LiFE, structure exercise, and control groups had 21, 24, and 26 people who fell once, and 39, 41, and 45 who fell at least twice, respectively. Median length of follow-up for all participants was 365 days (range 2-468, interquartile range 357-372). The overall incidence of falls in the LiFE programme was 1.66 per person years, compared with 1.90 in the structured programme and 2.28 in the control group. We recorded a clinically important reduction of $31 \%$ in the rate of falls for participants in the LiFE programme compared with the control programme (incidence rate ratio 0.69 (95\% confidence interval 0.48 to 0.99$), n=212$ ). We did not see a significant reduction in the fall rate for participants in the structured programme compared with the control programme $(0.81(0.56$ to 1.17$), \mathrm{n}=210$ )

Tables 2 to $5 \Downarrow \Downarrow \Downarrow \Downarrow$ present the secondary measures summarising the major outcomes. If the general linear modelling analysis was significant for all three programmes, we then confirmed which of the interventions was effective through pairwise analysis. We also presented Cohen effect sizes to provide an indication of clinical effectiveness for easier interpretation.

\section{Balance and strength}

Tables 2 and 3 summarise the findings for balance and strength outcomes over the 12 month study follow-up. LiFE participants significantly improved compared with controls, with moderate to large effect sizes for the two balance hierarchy scales. The structured programme showed small and significant effects for the five level scale (table 2). Dynamic balance measured by the timed tandem walk showed a significant and moderate effect for both the LiFE and structured programme compared with the control programme. Ankle strength significantly improved in the LiFE programme compared with controls (table 3). Knee and hip strength changes were not significant for either programme because the control group also made some intermittent gains.

\section{Functional outcomes}

Table 4 summarises secondary findings for functional measures. Activities of daily living using the NHANES measure was significantly improved for the LiFE participants compared with controls, with a moderate effect size. The Late Life Function Index showed large and significant effects for LiFE and a moderate and significant effect for the structured programme. The measure of participation, the Late Life Disability Index (frequency), was significantly improved for the LiFE group, with a moderate effect size. Both LiFE and structured programmes made significant gains in balance confidence, with small to moderate effect sizes (table 4). Physical activity, measured by the Physical Activity Scale for the Elderly, showed small but significant gains for the LiFE programme.

\section{Other secondary outcomes}

The Paffenbarger scales showed increased energy expenditure by both the LiFE and structured programmes, with moderate and small effects, respectively (table 5). The life space index showed no change in temporal range of activity spaces. Health status, measured by the itemised questions of the EQ-5D, did not differ significantly between groups, however, when participants were asked to rate their health status using the EQ-VAS scale, LiFE participants reported a significantly better health status at 12 months. We saw no significant difference in fat free mass. Body mass index showed that the controls increased their body mass index, which was significant compared with the structured group.

\section{Adverse events}

Two patients reported severe adverse effects that they attributed to the exercise programme. One participant in the structured programme had a groin strain and surgery for an inguinal hernia and ceased the programme; a LiFE participant was diagnosed with a pelvic stress fracture and attributed this to increased walking and stair climbing, but continued on the programme.

\section{Adherence}

Table $6 \Downarrow$ shows the mean proportion of adherence to each exercise programme over the first six months; the structured programmed showed a significant group effect $(\mathrm{P}=0.01)$ with the lowest adherence. Retrospective analysis confirmed that the adherence to the structured programme was significantly lower than either the LiFE programme (mean difference $0.12, t=2.82$, $\mathrm{P}<0.01)$ or the control programme $(0.13,2.66, \mathrm{P}<0.01)$.

Although each programme had similar numbers of participants who withdrew at six months of follow-up, the pattern for poor adherence (that is, $\leq 25 \%$ ) varied between the three programmes (table $7 \Downarrow$ ).

There were 68 (64\%) participants exercising at 12 months in the LiFE programme (seven $(6.5 \%)$ did not return records but provided self reports), 56 (53\%, including $12(11.4 \%)$ self reports) in the structured programme, and $56(53 \%$, including seven $(6.7 \%)$ self reports) in the control programme. Of $61 \mathrm{LiFE}$ participants who completed exercise records, the mean number of days in which the exercises were done per week in the final month was 3.89 (standard deviation 2.13; interquartile range 2.24-6.00), of a maximum seven days. Of 44 participants in the structured programme who returned exercise records and were exercising at 12 months, $43(98 \%)$ were still doing the balance exercises, 26 (59\%) were doing strength exercises with rod weights (weight range 1-6.5 kg, median $5 \mathrm{~kg}$ ), and four (9\%) were doing isometric strength exercises.

\section{Discussion}

LiFE is a tailored programme of embedded balance and strength activities, taught over five home visits with two booster visits. It was designed to reduce fall risk and resulted in a clinically important $31 \%$ reduction in the rate of falls compared with the control programme, which involved gentle sham exercise. A $30 \%$ reduction in falls is similar to most interventions currently recommended for fall prevention in clinical guidelines. The structured lower limb strength and balance exercises, taught over a similar time frame and prescribed three times a week, did not show significant results, with a $19 \%$ reduction in the 
rate of falls compared with the controls. Furthermore, the LiFE programme was superior in terms of function and participation, providing support that this programme mediates both fall risk and frailty.

LiFE programme participants improved in both static and dynamic balance, showing moderate effect sizes with the strongest effect observed into the high end static balance measure. The structured programme showed a small effect on static balance and a moderate effect on dynamic balance. The importance of balance, as the most important exercise component in mediating fall risk, was highlighted in a systematic review of 44 exercise trials, ${ }^{4}$ which examined trials in terms of both fall outcome and exercise intensity. Training in control of postural sway seems to affect the vestibular system by improving individual capacity to regain and control balance..$^{30}$ The functional activities in the LiFE programme also translated into moderate changes in ankle strength. Ankle strength is understood to be a prime factor for an effective strategy for the ankle when a pertubation occurs, and therefore is protective of falls. ${ }^{31}$ While LiFE showed steady improvements, all programmes made variable gains for knee and hip strength.

Two other exercise programmes to prevent falls have reported physical activity outcomes using the Physical Activity Scale for the Elderly. ${ }^{32}{ }^{33}$ Both reported less deterioration in controls than in the intervention group, whereas we reported an increase in physical activity in both the structured and control programmes, with a small significant effect for the LiFE programme. The strong response from the Paffenbarger measure of energy expenditure for LiFE could be linked to its use of increased physical activity, in particular stair climbing, for many participants. The LiFE programme also had better outcomes than the structured programme on the functional and daily activity measures, with significant and moderate to large effect sizes for LiFE participants. This effect suggests that the LiFE programme could improve functional capacity in frail older people. There might be value in testing whether the LiFE programme and philosophy could be introduced at a younger and earlier stage, to mediate functional decline whether or not a person has experienced a fall.

The LiFE programme is unique and novel; no other interventions have used a tailored approach to embedded exercise with functional activity. We did find three other programmes offering either structured exercise that included functional movement or specific balance tasks that showed positive outcomes. These programmes perhaps lend some support to the effects of the integration component of the LiFE programme. ${ }^{34-36}$

Dual tasking LiFE activities include a range of activities and can upgrade balance and strength challenges in small but incremental ways. For some people, these exercises have included ironing while standing on one leg, talking on the phone while heel standing and moving to limits of stability, carrying a tray or drink in a cup while tandem walking, squatting in the supermarket to select an item from a lower shelf rather than bending, and carrying the groceries from the car to the porch while walking sideways. Emerging evidence suggests that a person's capacity for dual tasking can predict their risk of falls, particularly capacity for tasks that involve gait variability and attention demanding tasks, ${ }^{37}$ with increased risk for repeat fallers. ${ }^{38}$. Furthermore, training in specific dual task activities to challenge balance in older people, undertaken in clinics, has been shown to improve gait stride and variability, and dynamic and static balance. However, these clinic interventions have not been shown to be transferable to novel situations. ${ }^{30}$
Tailored and embedded activity that aligns with functional conditions and everyday tasks could enhance integration of skills such as task co-ordination, postural control, and spatial processing. Along with physiological changes, these activities could lead to translation of protective skills in other situations. Liu-Ambrose and colleagues ${ }^{39}$ presented a central benefit model of exercise for fall prevention, arguing that the contribution of attention, dual tasking, planning, and other executive functioning might be just as important as physiological outcomes. The LiFE approach shows that a sole exercise intervention designed to prevent falls can have a clinically important effect on function at the level of participation engagement. ${ }^{40}$

Adherence was significantly better in the LiFE programme and control group than in the structured exercise programme, which was evident in the detailed frequency analysis over the first six months. All three programmes maintained a good adherence at 12 months, although adherence to the LiFE programme remained superior. All programmes exceeded the $42 \%$ adherence reported in the New Zealand Otago trial, which tested a successful exercise programme that was structured and home based. ${ }^{32}$ The measures of intensity varied for each programme, making an exact comparison difficult. The structured programme in our study had less follow through with the strength component, although our results were still near to the Otago result. In our study, therapists commented that many older participants struggled with the cumbersome nature of the weight cuffs, and we recommend investment in better designs. Many participants in the control group made comments; some liked the gentle exercise and others regarded them as “too easy' and not meeting their needs.

The lower performance of the structured programme in terms of a falls outcome might also be due to the range of challenge activities and upgrades needing to be enhanced. In addition, recruitment of participants with recurrent or injurious falls resulted in a higher risk group with multiple problems in our study than in the New Zealand Otago trial. ${ }^{32}$

\section{Limitations}

The control group received less contact time than both interventions, which could have caused a bias, but we saw no difference in the return rates of fall surveillance diaries, so this is unlikely. Also, adherence to the control and LiFE programmes was similar over the first six months, which spanned the interventionists' follow-up phase. The falls outcome for the LiFE programme was significantly different from controls; however, the higher confidence interval was close to 1 , indicating some caution with interpretation of these results, and further research with the LiFE intervention should aim to replicate our findings. The strong outcomes of the secondary measures point to clear mediators of benefit and confirm there was a positive fall outcome. The control group had an intervention that could have diluted the effect of the outcomes. Since the control exercises were gentle, flexible, mostly non-weightbearing, and not upgraded by the therapists, their effect on fall reduction or balance would have been marginal, ${ }^{41-43}$ although we did observe some minimal strength improvements.

Our study had a slightly lower sample size than preferred, which could have led to a type II error. If we had greater power to detect a difference, the confidence interval would probably have been narrower. Furthermore, the fall rate was higher than expected, which could also reduce the required sample size. Despite these limitations, we did find statistical significance. The pilot study, matched against a control programme of no intervention, showed a large reduction of falls, adding further 
support to our findings. A meta-analysis combining the pilot study ${ }^{9}$ and our current findings gave an incidence rate ratio of 0.63 (95\% confidence interval 0.45 to 0.90$)$, using Comprehensive Meta-Analysis software (version 2).

\section{Conclusion}

The LiFE programme provides an additional choice to traditional exercise and another fall prevention programme that could work for some people. Functional based exercise should be a focus for protection from falling and for improving and maintaining functional capacity for older people at risk. The programme has many positive outcomes: increased energy to do more tasks, improved function during activities, and enhanced participation in daily life. In a modern world that increasingly relies on increased automation and doing less, the LiFE programme provides a beneficial environment that offers some stressors and complexity. Furthermore, it challenges allied health professionals to expand their focus when working with older people to find opportunities to incorporate balance and strength training into daily life.

We thank Jo Munro for her contribution to the development of the LiFE programme, Elvina Weissel for her support, the Department of Veteran's Affairs for assistance with recruitment, Melissa Abela for compiling the six month adherence data, and Augustus Yip for preparing the body composition estimates.

Contributors: LC (principal investigator) designed the study and protocol, led the development of the LiFE programme, wrote the grant application, analysed data, interpreted results, and wrote the paper. LC is guarantor. MAFS contributed to the study design, grant application, and development of the LiFE programme; provided the structured and control programmes; and contributed to the interpretation of study results and writing of the paper. $\mathrm{AB}$ contributed to the study design, grant application, interpretation of results, and writing of the paper. RGC contributed to the study design, grant application, interpretation of study results, and writing of the paper. KM recruited participants, conducted assessments, and managed and cleaned the data. PO conducted interventions, managed the intervention team, and collected adherence data. DB provided advice on statistical analysis, interpretation of results, and writing of the paper.

Funding: The trial was funded by a project grant from the National Health and Medical Research Council.

Competing interests: All authors have completed the Unified Competing Interest form at www.icmje.org/coi_disclosure.pdf (available on request from the corresponding author) and declare: support from the National Health and Medical Research Council; no financial relationships with any organisations that might have an interest in the submitted work in the previous three years, no other relationships or activities that could appear to have influenced the submitted work.

Ethical approval: This study was approved by the University of Sydney human ethics committee.

Data sharing: Requests for data sharing should be directed to LC and would be considered as required.

Study protocol available from corresponding author.

1 Bleijlevens MHC, Diederiks JPM, Hendriks MRC, van Haastregt JCM, Crebolder HFJM, van Eijk JTM. Relationship between location and activity in injurious falls: an exploratory study. BMC Geriatrics 2010:10:40.

2 Watson W, Clapperton A, Mitchell RT. The incidence and cost of falls injury among older people in New South Wales 2006/07. NSW Department of Health, 2010.

3 Irwin M, Hayen A, Finch C. Methodological issues in using routinely collected electronic population mortality data: guidelines for using the national coroners information system for fatal injury surveillance in NSW. 2008. www.irmrc.unsw.edu.au/documents/ NCISreport08.pdf.

4 Sherrington C, Whitney JC, Lord SR, Herbert RD, Cumming RG, Close JCT. Effective exercise for the prevention of falls: a systematic review and meta-analysis. J Am Geriatric Soc 2008;56:2234-43.
5 NSW Department of Health. Annual report 2006/07. State Government of New South Wales, 2007.

6 Andersen REP, Wadden TAP, Bartlett SJP, Zemel BP, Verde TJP, Franckowiak SC. Effects of lifestyle activity versus structured aerobic exercise in obese women: a randomized trial. JAMA 1999;281:335-40.

7 Dunn AL, Marcus BH, Kampert JB, Garcia ME, Kohl HW, Blair SN. Comparison of lifestyle and structured interventions to increase physical activity and cardiorespiratory fitness: a randomized trial. JAMA 1999:281:327-34.

8 Opdenacker J, Boen F, Coorevits N, Delecluse C. Effectiveness of a lifestyle intervention and a structured exercise intervention in older adults. Prev Med 2008;46:518-24.

9 Clemson L, Fiatarone Singh M, Bundy AC, Cumming RG, Weissel E, Munro J, et al. LiFE Pilot Study: a randomised trial of balance and strength training embedded in daily life activity to reduce falls in older adults. Aust Occup Ther J 2010;57:42-50.

10 RALLOC. Stata module to design randomized controlled trials [program]. 2006. http:// ideas.repec.org/c/boc/bocode/s319901.html.

11 Clemson L. Fall risk behavior. In: Gellman MD, Turner JR, eds. Encyclopedia of behavioral medicine. Springer, 2012.

12 Friery L. Rasch analysis of the LiFE assessment of functional balance and strength University of Sydney, 2007

13 Clemson L, Fiatarone Singh M, Munro J. Lifestyle-integrated Functional Exercise (LiFE) reducing falls and improving function. Participant manual, 2007.

14 Fiatarone Singh MA, Murphy K. Helping elders activate their lives. HEAL program training manual for staff and exercise leaders. Hebrew Rehabilitation Center for the Aged \& Fit for Your Life Foundation Ltd, 2003.

15 Davis JC, Ashe MC, Liu-Ambrose T, Khan KM, Robertson MC, Marra CA. Does a home based strength and balance programme in people aged $\geq 80$ years provide the best value for money to prevent falls? A systematic review of economic evaluations of falls prevention interventions. BMJ 2009: published online 6 August.

16 Guralnik JM, Simonsick EM, Ferrucci L, Glynn RJ, Berkman LF, Blazer DG, et al. A short physical performance battery assessing lower extremity function: association with self-reported disability and prediction of mortality and nursing home admission. J Gerontol 1994;49:M85-94.

17 Linacre J. WINSTEPS Rasch measurement computer program. Winsteps.com, 2006.

18 Talley KMC, Wyman JF, Gross CR. Psychometric properties of the activities-specific balance confidence scale and the survey of activities and fear of falling in older women. J Am Geriat Soc 2008;56:328-33.

19 Haley SM, Jette AM, Coster WJ, Kooyoomjian JT, Levenson S, Heeren T, et al. Late life function and disability instrument: II. Development and evaluation of the function component. J Gerontol Ser A 2002;57:M217-22.

20 Finucane $\mathrm{F}$, Freid VM, Madans $\mathrm{JH}$, et al. Plan and operation of the NHANES Epidemiologic Followup Study. Vital Health Stat 1990;25:1-154.

21 Jette AM, Haley SM, Coster WJ, Kooyoomjian JT, Levenson S, Heeren T, et al. Late life function and disability instrument: I. Development and evaluation of the disability component. J Gerontol Ser A 2002;57:M209-16.

22 Washburn RA, McAuley E, Katula J, Mihalko S, Boileau R. The Physical Activity Scale for the Elderly (PASE): evidence for validity. J Clin Epidemiol 1999;52:643-51.

23 Paffenbarger RS, Wing AL, Hyde RT. Physical activity as an index of heart attack risk in college alumni. Am J Epidemiol 1978;108:161-75.

24 Baker PS, Bodner EV, Allman RM. Measuring life-space mobility in community dwelling older adults. J Am Geriatr Soc 2003;51:1610-14.

25 The EuroQol Group. EuroQol—a new facility for the measurement of health-related quality of life. Health Policy 1990;16:199-208.

26 Sun SS, Chumlea WC, Heymsfield SB, Lukaski HC, Schoeller D, Friedl K, et al. Development of bioelectrical impedance analysis prediction equations for body composition with the use of a multicomponent model for use in epidemiologic surveys. Am J Clin Nutrition 2003:77:331-40.

27 Robertson MC, Campbell AJ, Herbison P. Statistical analysis of efficacy in falls prevention trials. J Gerontol Ser A 2005;60:530-4.

28 Thalheimer W, Cook S. How to calculate effect sizes from published research: a simplified methodology. 2002. http://education.gsu.edu/coshima/EPRS8530/Effect_Sizes_pdf4.pdf.

29 Moher D, Hopewell S, Schulz KF, Montori V, Gøtzsche PC, Devereaux PJ, et al. CONSORT 2010 explanation and elaboration: updated guidelines for reporting parallel group randomised trials. $B M J$ 2010;340:c869.

30 Silsupadol P, Lugade V, Shumway-Cook A, van Donkelaar P, Chou L-S, Mayr U, et al. Training-related changes in dual-task walking performance of elderly persons with balance impairment: a double-blind, randomized controlled trial. Gait Posture 2009;29:634-9.

31 Menz HB, Morris ME, Lord SR. Foot and ankle characteristics associated with impaired balance and functional ability in older people. J Gerontol Ser A 2005;60:1546-52.

32 Campbell AJ, Robertson MC, Gardner MM, Norton RN, Tilyard MW, Buchner DM. Randomised controlled trial of a general practice programme of home based exercise to prevent falls in elderly women. BMJ 1997;315:1065-9.

33 Clemson L, Cumming RG, Kendig H, Swann M, Heard R, Taylor K. The effectiveness of a community-based program for reducing the incidence of falls among the elderly: a randomized trial. J Am Geriatr Soc 2004:52:1487-94.

34 Jaques-Dalcroze E, ed. Rhythm, music and education. Dalcroze Society, 1967.

35 Trombetti A, Hars M, Herrmann FR, Kressig RW, Ferrari S, Rizzoli R. Effect of music-based multitask training on gait, balance, and fall risk in elderly people: a randomized controlled trial. Arch Intern Med 2011;171:525-33.

36 Kuptniratsaikul V, Praditsuwan R, Assantachai P, Ploypetch T, Udompunturak S, Pooliam $\mathrm{J}$. Effectiveness of simple balancing training program in elderly patients with history of frequent falls. Clin Interventions Aging 2011;6:111-7.

37 Beauchet O, Annweiler C, Dubost V, Allali G, Kressig RW, Bridenbaugh S, et al. Stops walking when talking: a predictor of falls in older adults? Europ J Neurol 2009;16:786-95

38 Faulkner KA, Redfern MS, Cauley JA, Landsittel DP, Studenski SA, Rosano C, et al. Multitasking: association between poorer performance and a history of recurrent falls. $J$ Am Geriatr Soc 2007;55:570-6.

39 Liu-Ambrose T, Nagamatsu LS, Hsu LC, Bolandzadeh N. Emerging concept: "central benefit model" of exercise in falls prevention. Br J Sports Med 2012: published online 20 April.

40 Fairhall N, Sherrington C, Clemson L, Cameron ID. Do exercise interventions designed to prevent falls affect participation in life roles? A systematic review and meta-analysis. Age Ageing 2011;40:666-74.

41 Buchner DM, Cress ME, Wagner EH, de Lateur BJ, Price R, Abrass IB. The Seattle FICSIT/Movelt Study: the effect of exercise on gait and balance in older adults. $J$ Am Geriatr Soc 1993;41:321-5. 


\section{What is already known on this topic}

Balance and strength training is known to reduce falls in older adults

However, less than $10 \%$ of older people routinely engage in strength training and is probably lower for activities that challenge balance

\section{What this study adds}

The Lifestyle integrated Functional Exercise (LiFE) programme provides an alternative to traditional exercise for older people to reduce falls, to improve function in doing activities and to enhance participation in daily life

The LiFE programme demonstrates that having an environment that offers some stressors and complexity is beneficial

42 Province MA, Hadley EC, Hornbrook MC, Lipsitz LA, Miller JP, Mulrow CD, et al. The effects of exercise on falls in elderly patients: a preplanned meta-analysis of the FICSIT trials. JAMA 1995;273:1341-7.

43 Lord S, Castell S, Corcoran J, Dayhew J, Matters B, Shan A, et al. The effect of group exercise on physical functioning and falls in frail older people living in retirement villages: a randomized controlled trial. J Am Geriatr Soc 2003;51:1685-92.

Accepted: 07 June 2012

\section{Cite this as: BMJ 2012;345:e4547}

This is an open-access article distributed under the terms of the Creative Commons Attribution Non-commercial License, which permits use, distribution, and reproduction in any medium, provided the original work is properly cited, the use is non commercial and is otherwise in compliance with the license. See: http://creativecommons.org/licenses/by$\mathrm{nc} / 2.0 /$ and http://creativecommons.org/licenses/by-nc/2.0/legalcode. 


\section{Tables}

Table 1| Demographic and health status of trial participants at baseline. Data are no $(\%)$ of participants unless stated otherwise LiFE programme $(n=107)$ Structured exercise $(n=105)$ Control (gentle exercise) $(n=105)$

\begin{tabular}{lccc} 
Age (years; mean (SD)) & $82.81(4.48)$ & $84.03(4.38)$ & $83.47(3.81)$ \\
\hline Female sex & $59(55.1)$ & $57(54.3)$ & $58(55.2)$ \\
\hline No of falls in past year (mean (SD)) & $2.13(1.47)$ & $2.21(1.80)$ & $2.07(1.10)$ \\
\hline Injurious falls in past year & $101(94)$ & $96(91)$ & $14(13)$ \\
\hline History of stroke & $14(13)$ & $59(33)$ & $11(11)$ \\
\hline Has chronic illness & $63(35)$ & $37(35)$ & $59(33)$ \\
\hline Hospital admissions past year & $41(38)$ & $5.4(2.8)$ & $50(47)$ \\
\hline No of drugs prescribed (mean (SD)) & $5.5(3.7)$ & $6.4(4.0)$ & $4.6(2.8)$ \\
\hline Geriatric depression scale score (mean (SD)) & $5.9(3.7)$ & $6.2(3.9)$ &
\end{tabular}

$\mathrm{SD}=$ standard deviation 


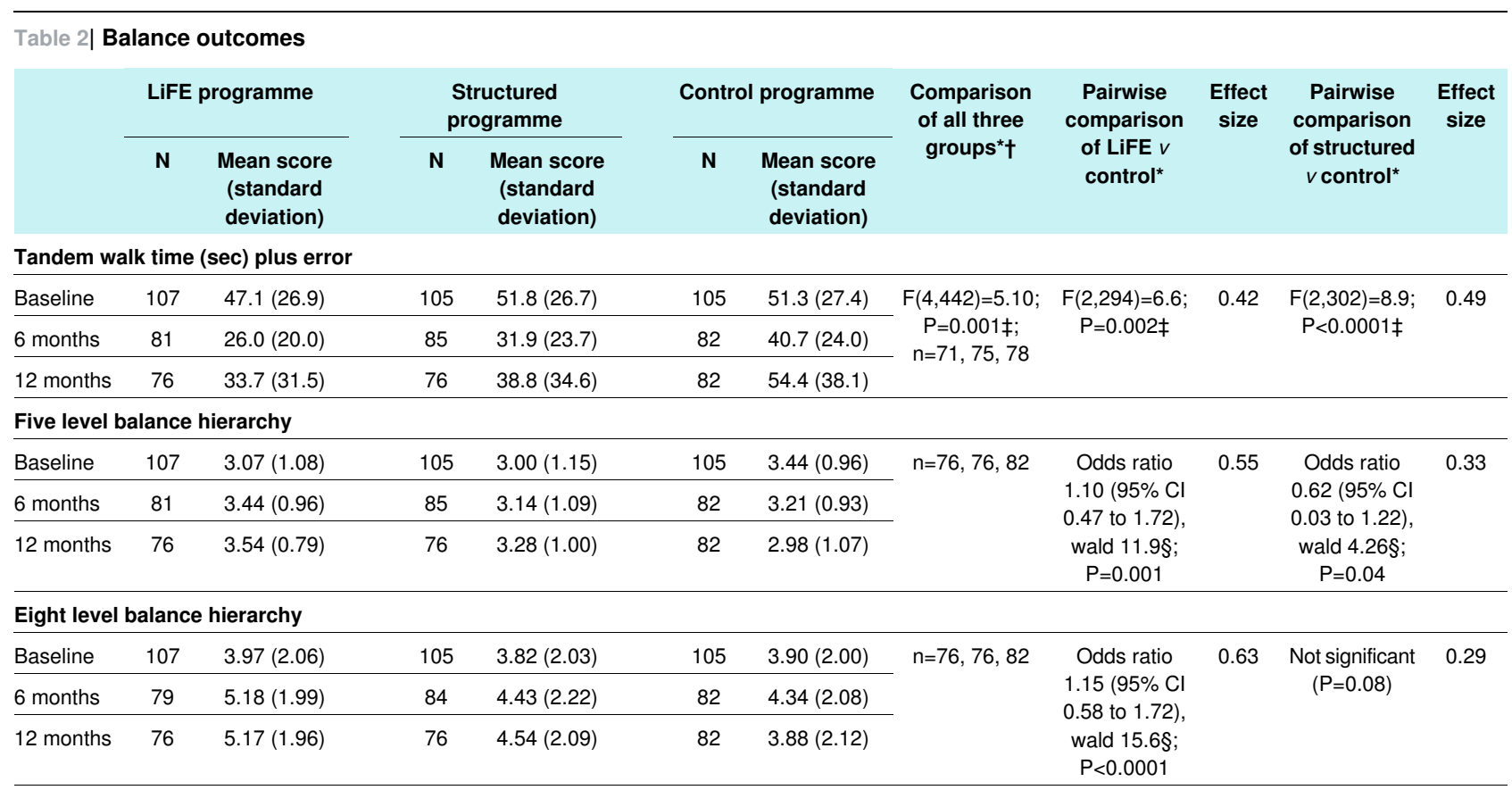

*Main effect timexintervention: $F(d f$, error)=measure of variation between groups divided by variation within groups; $P$ value. †No of participants in LiFE, structured exercise, and control groups, respectively. $\ddagger$ Skewed data transformed before analysis.

§Polynomial regression model used with rank order categorical data. 


\begin{tabular}{|c|c|c|c|c|c|c|c|c|c|c|c|}
\hline \multicolumn{12}{|c|}{ Table 3| Strength outcomes } \\
\hline & \multicolumn{2}{|c|}{ LiFE programme } & \multicolumn{2}{|c|}{$\begin{array}{c}\text { Structured } \\
\text { programme }\end{array}$} & \multicolumn{2}{|c|}{ Control programme } & \multirow[b]{2}{*}{$\begin{array}{l}\text { Comparison of } \\
\text { all three } \\
\text { groups }{ }^{*} \dagger\end{array}$} & \multirow{2}{*}{$\begin{array}{l}\text { Pairwise } \\
\text { comparison } \\
\text { of LiFE } v \\
\text { control }^{\star}\end{array}$} & \multirow[b]{2}{*}{$\begin{array}{l}\text { Effect } \\
\text { size }\end{array}$} & \multirow{2}{*}{$\begin{array}{c}\text { Pairwise } \\
\text { comparison } \\
\text { of } \\
\text { structured } v \\
\text { control }^{*}\end{array}$} & \multirow[b]{2}{*}{$\begin{array}{l}\text { Effect } \\
\text { size }\end{array}$} \\
\hline & $\mathbf{N}$ & $\begin{array}{c}\text { Mean score } \\
\text { (standard } \\
\text { deviation) }\end{array}$ & $\mathbf{N}$ & $\begin{array}{c}\text { Mean score } \\
\text { (standard } \\
\text { deviation) }\end{array}$ & $\mathbf{N}$ & $\begin{array}{c}\text { Mean score } \\
\text { (standard } \\
\text { deviation) }\end{array}$ & & & & & \\
\hline \multicolumn{12}{|c|}{ Right ankle strength (mean kg force) } \\
\hline Baseline & 107 & $11.7(4.8)$ & 105 & $12.1(5.2)$ & 104 & $11.9(4.3)$ & \multirow{3}{*}{$\begin{array}{c}F(3.8,399)=2.66 \ddagger \\
P=0.035 ; n=68 \\
71,75\end{array}$} & \multirow{3}{*}{$\begin{array}{c}F(2,282)=5.5 \\
\quad P=0.005\end{array}$} & \multirow[t]{3}{*}{0.40} & \multirow{3}{*}{$\begin{array}{c}\text { Not } \\
\text { significant } \\
(\mathrm{P}=0.10)\end{array}$} & \multirow[t]{3}{*}{0.26} \\
\hline 6 months & 81 & $13.5(5.0)$ & 82 & $12.9(5.0)$ & 82 & $12.3(4.8)$ & & & & & \\
\hline 12 months & 72 & $13.8(4.8)$ & 74 & $13.1(5.5)$ & 80 & $12.3(5.2)$ & & & & & \\
\hline \multicolumn{12}{|c|}{ Left ankle strength (mean $\mathrm{kg}$ force) } \\
\hline Baseline & 107 & $11.4(4.5)$ & 105 & $12.1(5.1)$ & 105 & $12.0(4.9)$ & \multirow{3}{*}{$\begin{array}{c}\mathrm{F}(3.8,405)=5.7 \ddagger \\
\mathrm{P}<0.0001 ; \mathrm{n}=68 \\
71,75\end{array}$} & \multirow{3}{*}{$\begin{array}{c}F(2,282)=8.6 \\
P<0.0001\end{array}$} & \multirow[t]{3}{*}{0.40} & \multirow{3}{*}{$\begin{array}{c}\text { Not } \\
\text { significant } \\
(\mathrm{P}=0.34)\end{array}$} & \multirow[t]{3}{*}{0.17} \\
\hline 6 months & 81 & $13.1(4.6)$ & 83 & $12.6(5.0)$ & 81 & $12.3(5.0)$ & & & & & \\
\hline 12 months & 72 & $13.8(4.8)$ & 73 & $12.5(5.4)$ & 80 & $12.4(5.0)$ & & & & & \\
\hline \multicolumn{12}{|c|}{ Right knee strength (mean kg force) } \\
\hline Baseline & 107 & $10.1(4.8)$ & 105 & $10.3(5.0)$ & 105 & $10.1(4.4)$ & \multirow{3}{*}{$\begin{array}{c}P=0.45 ; n=68,70 \\
75\end{array}$} & \multirow[t]{3}{*}{-} & \multirow[t]{3}{*}{-} & \multirow[t]{3}{*}{-} & \multirow[t]{3}{*}{-} \\
\hline 6 months & 81 & $11.3(4.4)$ & 82 & $10.9(4.5)$ & 82 & $10.6(4.7)$ & & & & & \\
\hline 12 months & 72 & $11.9(4.2)$ & 73 & $12.00(4.6)$ & 78 & $11.1(4.6)$ & & & & & \\
\hline \multicolumn{12}{|c|}{ Left knee strength (mean kg force) } \\
\hline Baseline & 107 & $9.0(4.4)$ & 105 & $10.1(5.4)$ & 104 & $9.7(4.4)$ & \multirow{3}{*}{$\begin{array}{c}P=0.21 ; n=69,69 \\
75\end{array}$} & \multirow[t]{3}{*}{-} & - & - & - \\
\hline 6 months & 81 & $10.2(4.4)$ & 84 & $10.0(4.2)$ & 81 & $10.0(4.4)$ & & & & & \\
\hline 12 months & 73 & $11.6(4.5)$ & 71 & $10.6(4.8)$ & 80 & $11.1(4.1)$ & & & & & \\
\hline Right hip s & rengtr & mean $\mathrm{kg}$ forc & & & & & & & & & \\
\hline Baseline & 107 & $7.1(3.1)$ & 105 & $7.8(3.8)$ & 104 & $7.5(2.8)$ & $P=0.09 \ddagger ; n=69$ & - & - & - & - \\
\hline 6 months & 81 & $8.0(3.3)$ & 84 & $8.0(3.8)$ & 82 & $7.5(3.0)$ & 13,13 & & & & \\
\hline 12 months & 73 & $9.0(3.0)$ & 75 & $8.7(3.8)$ & 78 & $8.3(3.1)$ & & & & & \\
\hline Left hip str & ngth & lean $\mathrm{kg}$ force & & & & & & & & & \\
\hline Baseline & 107 & $6.7(2.9)$ & 105 & $7.5(3.5)$ & 104 & $7.2(3.3)$ & $F(3.6,382)=3.1 \ddagger$ & - & - & - & - \\
\hline 6 months & 81 & $7.8(3.0)$ & 84 & $7.4(3.6)$ & 82 & $7.1(3.0)$ & 70,75 & & & & \\
\hline 12 months & 73 & $8.7(3.4)$ & 72 & $8.3(3.4)$ & 80 & $8.1(3.2)$ & & & & & \\
\hline
\end{tabular}

*Main effect timexintervention: $F(d f$, error)=measure of variation between groups divided by variation within groups. †No of participants in LiFE, structured exercise, and control groups, respectively.

¥Mauchley test of specificity significant, Greenhouse-Geisser reported. 


\begin{tabular}{|c|c|c|c|c|c|c|c|c|c|c|c|}
\hline \multicolumn{12}{|c|}{ Table 4 | Outcomes for secondary measures of function } \\
\hline & \multicolumn{2}{|c|}{ LiFE programme } & \multicolumn{2}{|c|}{$\begin{array}{l}\text { Structured } \\
\text { programme }\end{array}$} & \multicolumn{2}{|c|}{$\begin{array}{c}\text { Control } \\
\text { programme }\end{array}$} & \multirow[b]{2}{*}{$\begin{array}{l}\text { Comparison of } \\
\text { all three groups }\end{array}$} & \multirow[b]{2}{*}{$\begin{array}{c}\text { Pairwise } \\
\text { comparison of } \\
\text { LiFE } v \text { control }{ }^{*}\end{array}$} & \multirow[b]{2}{*}{$\begin{array}{l}\text { Effect } \\
\text { size }\end{array}$} & \multirow[b]{2}{*}{$\begin{array}{c}\text { Pairwise } \\
\text { comparison of } \\
\text { structured } v \\
\text { control }^{*}\end{array}$} & \multirow[b]{2}{*}{$\begin{array}{l}\text { Effect } \\
\text { size }\end{array}$} \\
\hline & N & $\begin{array}{c}\text { Mean } \\
\text { score } \\
\text { (standard } \\
\text { deviation) }\end{array}$ & $\mathbf{N}$ & $\begin{array}{c}\text { Mean } \\
\text { score } \\
\text { (standard } \\
\text { deviation) }\end{array}$ & $\mathbf{N}$ & $\begin{array}{c}\text { Mean } \\
\text { score } \\
\text { (standard } \\
\text { deviation) }\end{array}$ & & & & & \\
\hline \multicolumn{12}{|c|}{ Activities Specific Balance Confidence Scale } \\
\hline Baseline & 106 & $1079(283)$ & 105 & $1027(272)$ & 105 & $1048(328)$ & \multirow{3}{*}{$\begin{array}{c}\mathrm{F}(4,460)=3.75 \llbracket ; \\
\mathrm{P}=0.005 ; \mathrm{n}=75 \\
79,79\end{array}$} & \multirow{3}{*}{$\begin{array}{c}F(2,304)=5.52 \\
P=0.004\end{array}$} & \multirow[t]{3}{*}{0.38} & \multirow{3}{*}{$\begin{array}{c}F(2,312)=5.22 \\
P=0.006\end{array}$} & \multirow[t]{3}{*}{0.37} \\
\hline 6 months & 84 & $1228(242)$ & 86 & $1144(245)$ & 84 & $1112(308)$ & & & & & \\
\hline 12 months & 79 & $1208(275)$ & 80 & $1167(268)$ & 82 & $1085(302)$ & & & & & \\
\hline \multicolumn{12}{|c|}{ NHANES activities of daily life measure } \\
\hline Baseline & 107 & $0.85(0.46)$ & 105 & $0.93(.49)$ & 105 & $0.91(.51)$ & \multirow{3}{*}{$\begin{array}{c}\mathrm{F}(3.8,436)=4.74 \ddagger \\
\mathrm{P}=0.001 \ddagger ; \mathrm{n}=75 \\
79,80\end{array}$} & \multirow{3}{*}{$\begin{array}{c}F(1.9,292)=11.32 \\
P<0.0001\end{array}$} & \multirow[t]{3}{*}{0.54} & \multirow{3}{*}{$\begin{array}{l}\text { Not significant } \\
\quad(P=0.075)\end{array}$} & \multirow[t]{3}{*}{0.26} \\
\hline 6 months & 83 & $0.67(0.47)$ & 86 & $0.88(.40)$ & 85 & $0.95(.55)$ & & & & & \\
\hline 12 months & 79 & $0.74(0.52)$ & 80 & $0.90(.55)$ & 82 & $1.02(.54)$ & & & & & \\
\hline \multicolumn{12}{|c|}{ Late life function index } \\
\hline Baseline & 107 & $71.6(11.8)$ & 104 & $69.5(12.6)$ & 104 & $69.2(14.8)$ & \multirow{2}{*}{$\begin{array}{c}F(2,235)=9.13 \\
P<0.0001 ; n=79 \\
78,81\end{array}$} & \multirow{2}{*}{$\begin{array}{c}F(1,158)=21.05 \\
P<0.0001\end{array}$} & \multirow[t]{2}{*}{0.73} & \multirow{2}{*}{$\begin{array}{c}F(1,157)=6.66 \\
P=0.04\end{array}$} & \multirow[t]{2}{*}{0.41} \\
\hline 12 months & 79 & $76.5(14.3)$ & 79 & $71.9(12.9)$ & 82 & $68.3(15.8)$ & & & & & \\
\hline \multicolumn{12}{|c|}{ Late life disability index (frequency) } \\
\hline Baseline & 107 & $56.7(6.6)$ & 105 & $56.2(8.1)$ & 105 & $55.5(8.5)$ & \multirow{2}{*}{$\begin{array}{c}F(2,236)=4.66 \\
P=0.01 ; n=78,80 \\
81\end{array}$} & \multirow{2}{*}{$\begin{array}{c}F(1,157)=9.28 \\
P=0.003\end{array}$} & \multirow[t]{2}{*}{0.49} & Not significant & 0.17 \\
\hline 12 months & 78 & $58.4(7.2)$ & 80 & $56.3(8.4)$ & 81 & $54.8(7.6)$ & & & & $(P=0.28)$ & \\
\hline Late life disa & ability in & dex (limitation & & & & & & & & & \\
\hline Baseline & 107 & $70.1(8.7)$ & 105 & $69.4(9.6)$ & 105 & $69.4(9.9)$ & $F(2,236)=1.17$ & - & - & - & - \\
\hline 12 months & 78 & $69.2(11.9)$ & 80 & $67.5(12.1)$ & 81 & $66.4(11.1)$ & $\begin{array}{c}P=0.31 ; n=78,80 \\
81\end{array}$ & & & & \\
\hline Physical act & tivity sce & le for elderly & & & & & & & & & \\
\hline Baseline & 107 & $66.1(30.6)$ & 105 & $72.9(38.8)$ & 105 & $64.4(35.6)$ & $F(3.7,432)=2.3 \ddagger$ & $F(1.78,234)=3.28$ & 0.29 & Not significant & 0.05 \\
\hline 6 months & 84 & $67.8(36.8)$ & 86 & $61.0(37.4)$ & 85 & $52.3(26.8)$ & $\begin{array}{c}P=0.06 \S ; n=76 \\
78,80\end{array}$ & 11 & & & \\
\hline 12 months & 79 & $71.2(40.9)$ & 79 & $63.2(38.0)$ & 82 & $56.2(36.7)$ & & & & & \\
\hline $\begin{array}{l}{ }^{*} \text { Main effect } \\
\text { †No of partic } \\
\text { †Mauchley } t \\
\text { §Retrospect } \\
\text { ๆSkewed da }\end{array}$ & $\begin{array}{l}\text { cipants } \\
\text { test of } s \\
\text { tive Tuk } \\
\text { ata trans }\end{array}$ & $\begin{array}{l}\text { tervention; } F( \\
\text { n LiFE, struct } \\
\text { oecificity signi } \\
\text { ey analysis be } \\
\text { formed before }\end{array}$ & $\begin{array}{l}\text { exercis } \\
\text { Green } \\
\text { LifE } \\
\text { ysis. }\end{array}$ & $\begin{array}{l}\text { asure of variat } \\
\text { house-Geisse } \\
\text { and control gro }\end{array}$ & $\begin{array}{l}\text { ween } \\
\text {, resp } \\
\text { ted. } \\
=0.02\end{array}$ & $\begin{array}{l}\text { groups divide } \\
\text { eectively. }\end{array}$ & by variation wit & groups; P value. & & & \\
\hline
\end{tabular}




\begin{tabular}{|c|c|c|c|c|c|c|c|c|c|c|c|}
\hline \multicolumn{12}{|c|}{ Table 5| Outcomes for other secondary measures } \\
\hline & \multicolumn{2}{|c|}{ LiFE programme } & \multicolumn{2}{|c|}{$\begin{array}{c}\text { Structured } \\
\text { programme }\end{array}$} & \multicolumn{2}{|c|}{$\begin{array}{c}\text { Control } \\
\text { programme }\end{array}$} & \multirow[b]{2}{*}{$\begin{array}{c}\text { Comparison of all } \\
\text { three groups }{ }^{*} \dagger\end{array}$} & \multirow[b]{2}{*}{ 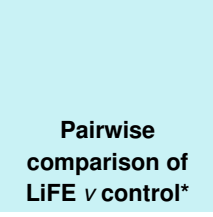 } & \multirow[b]{2}{*}{$\begin{array}{l}\text { Effect } \\
\text { size }\end{array}$} & \multirow[b]{2}{*}{$\begin{array}{c}\text { Pairwise } \\
\text { comparison of } \\
\text { structured } v \\
\text { control }^{*}\end{array}$} & \multirow[b]{2}{*}{$\begin{array}{l}\text { Effect } \\
\text { Size }\end{array}$} \\
\hline & $\mathbf{N}$ & $\begin{array}{c}\text { Mean } \\
\text { score } \\
\text { (standard } \\
\text { deviation) }\end{array}$ & $\mathbf{N}$ & $\begin{array}{l}\text { Mean score } \\
\text { (standard } \\
\text { deviation) }\end{array}$ & $\mathbf{N}$ & $\begin{array}{c}\text { Mean } \\
\text { score } \\
\text { (standard } \\
\text { deviation) }\end{array}$ & & & & & \\
\hline \multicolumn{12}{|c|}{ Paffenbarger physical activity index (energy expenditure; kcal/week) } \\
\hline Baseline & 107 & $419(651)$ & 10 & $\begin{array}{c}429 \\
(759) \\
\end{array}$ & 105 & $485(786)$ & \multirow{3}{*}{$\begin{array}{c}\mathrm{F}(4,462)=7.15 \Phi \\
\mathrm{P}<0.0001 ; \mathrm{n}=76 \\
78,80\end{array}$} & \multirow[t]{3}{*}{$\begin{array}{c}F(2,308)=15.01 \\
P<0.0001\end{array}$} & \multirow[t]{3}{*}{0.62} & \multirow[t]{3}{*}{$\begin{array}{c}F(2,312)=4.85 \\
P=0.008\end{array}$} & \multirow[t]{3}{*}{0.36} \\
\hline 6 months & 84 & $\begin{array}{c}1083 \\
(1261) \\
\end{array}$ & 86 & $\begin{array}{l}824 \\
(975) \\
\end{array}$ & 85 & $445(652)$ & & & & & \\
\hline 12 months & 79 & $\begin{array}{c}1576 \\
(1222) \\
\end{array}$ & 80 & $\begin{array}{c}1009 \\
(1116) \\
\end{array}$ & 82 & $660(1025)$ & & & & & \\
\hline \multicolumn{12}{|c|}{ Life space index (composite score) } \\
\hline Baseline & 107 & $67.3(21.5)$ & 105 & $62.5(20.4)$ & 105 & $60.8(22.0)$ & \multirow{3}{*}{$\begin{array}{c}F(3.8,436)=2.97 \ddagger \\
P=0.02\end{array}$} & \multirow[t]{3}{*}{-} & \multirow[t]{3}{*}{-} & \multirow[t]{3}{*}{-} & \multirow[t]{3}{*}{-} \\
\hline 6 months & 84 & $68.3(22.4)$ & 85 & $66.2(23.7)$ & 85 & $59.2(22.2)$ & & & & & \\
\hline 12 months & 78 & $65.6(24.8)$ & 81 & $58.7(22.3)$ & 82 & $54.9(20.9)$ & & & & & \\
\hline \multicolumn{12}{|c|}{ Health status questionnaire (EQ-5D) } \\
\hline Baseline & 107 & $7.1(1.4)$ & 105 & $6.9(1.5)$ & 105 & $7.0(1.4)$ & \multirow{3}{*}{$\begin{array}{c}F(3.89,452)=3.46 \ddagger \\
P=0.008 \S\end{array}$} & \multirow[t]{3}{*}{-} & \multirow[t]{3}{*}{-} & \multirow[t]{3}{*}{-} & \multirow[t]{3}{*}{-} \\
\hline 6 months & 84 & $6.6(1.3)$ & 86 & $6.9(1.5)$ & 85 & $7.2(1.6)$ & & & & & \\
\hline 12 months & 79 & $6.7(1.5)$ & 81 & $6.7(1.6)$ & 82 & $6.7(1.3)$ & & & & & \\
\hline \multicolumn{12}{|c|}{ Health status scale (EQ-VAS) } \\
\hline Baseline & 107 & $6.9(1.7)$ & 105 & $7.2(1.4)$ & 105 & $7.2(1.6)$ & \multirow{3}{*}{$\begin{array}{c}F(3.89,452)=3.36 \ddagger \\
P=0.01 ; n=76,79 \\
80\end{array}$} & \multirow{3}{*}{$\begin{array}{c}F(1.91,294)=4.46 \\
P=0.01\end{array}$} & 0.34 & Not significant & 0.06 \\
\hline 6 months & 84 & $7.5(1.4)$ & 86 & $7.4(1.7)$ & 85 & $7.3(1.7)$ & & & & & \\
\hline 12 months & 79 & $7.7(1.6)$ & 81 & $7.4(1.5)$ & 82 & $7.5(1.5)$ & & & & & \\
\hline Body mass & index & & & & & & & & & & \\
\hline Baseline & 107 & $25.9(4.8)$ & 105 & $26.6(3.9)$ & 104 & $26.4(4.2)$ & $F(3.32,379)=4.8 \ddagger ;$ & Not significant & 0.08 & $F(1.6,251)=7.7$ & 0.45 \\
\hline 6 months & 82 & $26.1(5.1)$ & 86 & $26.6(3.9)$ & 83 & $27.0(4.1)$ & $\begin{array}{c}P=0.002 ; n=74,79 \\
78\end{array}$ & $(P=0.26)$ & & $P=0.001$ & \\
\hline 12 months & 79 & $26.3(5.0)$ & 81 & 26.7(3.9) & 82 & $27.1(4.4)$ & & & & & \\
\hline Fat free ma & ss ind & & & & & & & & & & \\
\hline Baseline & 90 & $47.4(1.0)$ & 89 & $45.2(1.1)$ & 85 & $46.1(1.1)$ & $F(4,348)=0.20$ & - & - & - & - \\
\hline 6 months & 72 & $46.5(1.2)$ & 66 & $46.3(1.4)$ & 69 & $46.5(1.1)$ & $\begin{array}{c}P=0.94 ; n=63,54 \\
60\end{array}$ & & & & \\
\hline 12 months & 63 & $45.2(1.1)$ & 64 & $46.1(1.1)$ & 68 & $45.0(1.3)$ & & & & & \\
\hline
\end{tabular}

${ }^{*}$ Main effect timexintervention; $\mathrm{F}(\mathrm{df}, \mathrm{error})=$ measure of variation between groups divided by variation within groups; $\mathrm{P}$ value.

†No of participants in LiFE, structured exercise, and control groups, respectively.

¥Mauchley test of specificity significant, Greenhouse-Geisser reported.

§Quadratic contrast significant, linear non-significant

IData were skewed, and therefore had to be transformed before analysis. 
Table 6| Analysis of variance for adherence to exercise programmes over first six months

\begin{tabular}{lcccc} 
Programme & No of participants & Proportion (\%) of adherence (mean (standard deviation)) & F ratio & P \\
\cline { 1 - 4 } LiFE & 107 & $47(33)$ & 4.69 & 0.01 \\
\hline Structured exercise & 105 & $35(29)$ & \\
\hline Control & 105 & $47(34)$ & - & - \\
\hline Total & 317 & $43(36)$ & & -
\end{tabular}


Table 7| Exercise status over six months. Data are no (\%) of participants

LiFE programme $(n=107)$ Structured programme $(n=105)$ Control programme $(n=105)$

\begin{tabular}{lccc} 
Still exercising at end of six months & $81(76)$ & $63(60)$ & $74(71)$ \\
\hline Poor adherence $(\leq 25 \%)$ in first six months & $7(7)$ & $20(19)$ & $12(11)$ \\
\hline Out of study or withdrawn from exercises & $19(18)$ & $22(21)$ & $19(18)$ \\
\hline
\end{tabular}




\section{Figure}

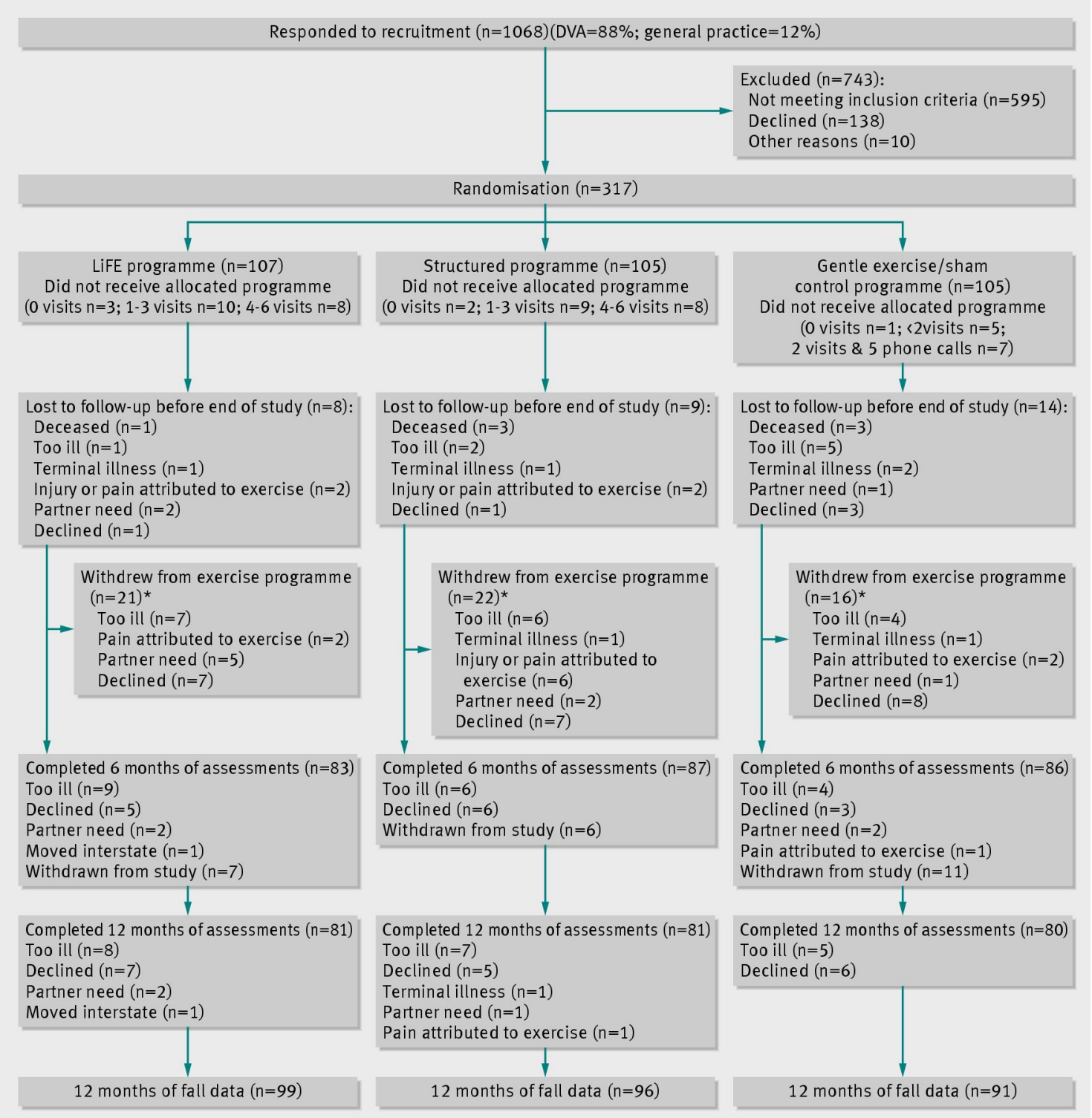

Flow chart of trial participants. * Requested to discontinue the exercise programme; does not include some participants who were not exercising in the final month (LiFE, $n=10$; structured, $n=18$; control, $n=19$ ) 